\title{
$\mathrm{MR}$ 유체물성과 오리피스 형상에 대한 MR 댐퍼 성능비교 연구
}

\author{
권영철 ${ }^{1}$, 박삼진 $^{1}$, 김기영 ${ }^{1}, ﹎{h}$ 대성 ${ }^{1}$, 이석현 ${ }^{*}$ \\ ${ }^{1}$ 선문대학교 기계공학과

\section{Study on Performance Comparison of MR Damper for Fluid Properties and Orifice Shapes}

\author{
Young-Chul Kwon ${ }^{1}$, Sam-Jin Park ${ }^{1}$, Ki-Young Kim ${ }^{1}$, Dae-Sung Baek ${ }^{1}$ \\ and Seok-Hyun Lee $^{1^{*}}$ \\ ${ }^{1}$ Dept. of Mechanical Eng., Sunmoon University
}

\begin{abstract}
요 약 MR 댐퍼는 자기장의 영향으로 인한 MR 유체의 응집현상으로 자기전단력을 발생한다. MR 유체는 기존유체 와 자기입자로 구성되어 있다. 본 연구에서 밀도 $1.3,1.5,1.7 \mathrm{~g} / \mathrm{cm}^{3}$ 그리고 점도 $1,000,10,000 \mathrm{cP}$ 를 가지는 $\mathrm{MR}$ 유체 6 종과 오리피스 형상 6종에 대한 MR 댐퍼의 댐핑력을 조사하였다. MR 유체의 밀도와 점도 변화에 따라서 MR 댐퍼 의 댐핑력이 변하였다. 오리피스 형상변화에 대한 댐핑력은 오리피스 갭이 적고 길이가 짧을수록 크게 나타났다. 이 들 연구결과로부터 MR 댐퍼의 최적설계를 위해서는 MR 유체의 선정과 오리피스 형상이 중요한 설계변수임을 확인 하였다.
\end{abstract}

\begin{abstract}
MR(Magneto-Rheological) damper generates the magnetic shear force due to the cohesiveness of MR fluid influenced by a magnetic field. MR fluid consists of magnetic particles and a base liquid. In the present study, the damping forces of MR damper were investigated for density $1.3,1.5$ and $1.7 \mathrm{~g} / \mathrm{cm}^{3}$, and viscosity 1000 and $10000 \mathrm{cp}$, and for the change of orifice shapes. It was found that the increase in the density and viscosity of MR fluid could change the damping force of MR damper due to the magnetic effects. Also, the damping forces on orifice shapes increased as the orifice gap and length decreased. These results showed that the properties of MR fluid and orifice shapes were important for the optimum design of MR damper.
\end{abstract}

Key Words : Damping force, Density, MR damper, MR fluid, Orifice, Viscosity

\section{1. 서론}

차량 및 정밀 시스템의 기계적 유발진동에 의한 진동 을 줄이기 위해서는 진동 폭을 줄이는 것이 가장 효율적 이다. 기계에 의한 진동의 발생을 방지하기 위해 진동 제 어 방법이 다방면에서 제안되었고, 그 중 능동적인 제어 가 가능한 MR(Magneto-Rheological) 댐퍼에 관한 연구가 국내에서 진행되고 있다. MR 댐퍼의 개발을 위해서는 $\mathrm{MR}$ 유체의 적용가능성과 운전특성을 체계적으로 조사하 여야 한다. 그리고 $\mathrm{MR}$ 댐퍼의 정밀 운전 제어를 위해서
는 자기장의 영향에 대한 $\mathrm{MR}$ 유체의 유체거동을 정확히 이해할 필요가 있다. MR 유체는 외부로부터 인가되는 자 기장의 세기에 따라 그 결합력이 변화하여

그에 상응하는 감쇄 전단력을 발생시킨다. 또한 MR 유체는 낮은 전류로도 우수한 성능구현이 가능하며 응답 반응속도가 빠르다. 또한 외부 불순물의 영향이 적고 상 대적인 운전소음이 낮아 기존 진동저감 분야 외에 정밀 분야까지 적용이 가능한 유체이다.

본 연구는 차량의 진동승차감 향상을 위한 차량 반능 동 현가장치용 MR 댐퍼 개발을 위해서 진행되었다. MR

본 연구의 일부는 지식경제부 산업원천기술개발사업의 지원으로 수행되었습니다.

${ }^{*}$ Corresponding Author : Seok-Hyun Lee(Sunmoon Univ.)

Tel: +82-10-7343-1868 email: noguleekill@naver.com

Received October 31, $2013 \quad$ Revised (1st November 25, 2013, 2nd November 26, 2013)

Accepted March 6, 2014 
댐퍼의 개발을 위해서는 MR 댐퍼에 사용되는 MR 유체 의 적용가능성과 운전특성을 먼저 조사하여야 한다. 그리 고 MR 댐퍼의 정밀 운전제어를 위해서는 자기장의 영향 을 받는 $\mathrm{MR}$ 유체의 동적거동을 정확히 이해하여야 한다. 이를 위해서는 체계적인 실험과 해석 방법을 활용하여 $\mathrm{MR}$ 유체의 유동특성과 자기장 특성을 심도있게 연구하 여야 한다.

MR 유체에 관한 연구는 1990년대부터 여러 연구기관 과 대학연구소를 중심으로 활발히 이루어지고 있다[1-3]. Jeon 등[4]은 원관 내부의 자기장에 의한 MR 유체의 특 징과 자연대류 현상을 연구하였다. 최근 Lee 등[5]은 다 양한 밀도와 점도를 가진 $\mathrm{MR}$ 유체들의 자기장에 의한 유동 가시화 연구를 수행하였다. 그리고 Baek 등[6]은 $\mathrm{MR}$ 댐퍼에 사용되는 $\mathrm{MR}$ 유체의 화학적 조성에 따른 물 리적 특성을 규명하고자 216종의 MR 유체를 제조하여 $\mathrm{MR}$ 유체의 분산 안정성과 물리적 특성을 조사하였다.

본 연구에서는 6 종(밀도 3 종, 점도 2 종)의 $\mathrm{MR}$ 유체를 $\mathrm{MR}$ 댐퍼에 적용하여 $\mathrm{MR}$ 유체의 밀도와 점도변화에 따 른 MR 댐퍼 성능을 비교하고자 하였다. 그리고 오리피스 치수 변경에 따른 MR 댐퍼의 성능을 비교하였다. 본 연 구로부터 획득된 $\mathrm{MR}$ 유체물성 따른 $\mathrm{MR}$ 댐퍼의 성능비 교 데이터는 MR 댐퍼의 최적설계를 위한 기초자료로 활 용될 수 있을 것이다.

\section{2. 실험조건 및 방법}

\subsection{MR 댐퍼 실험장치}

$\mathrm{MR}$ 댐퍼의 성능을 비교하기 위하여 MR 댐퍼 성능측 정 장비를 사용하였다. 장비는 펌프를 이용하여 유압을 공급해주는 동력부, 로드셀이 장착되어 있어 설치된 MR 댐퍼의 힘을 측정하는 센서부, 댐퍼에 일정하게 전류를 인가시켜주는 전력공급장치, 압력을 제어 하거나 센서부 에서 보내진 신호를 처리하는 제어부로 구성되어 있다. Fig. 1과 Table 1은 MR 댐퍼 시험장치와 주요 제원을 나 타낸다. Fig. 2는 실험에 사용된 MR 댐퍼를 보여준다. 본 실험에 사용된 MR 댐퍼는 피스톤의 운동으로 발생하는 댐퍼 내부의 가용 부피를 하단에 충진된 고압가스의 스 프링 작용으로 조절하는 방식이다. MR 댐퍼는 MR 유체 주입 시 공기가 유입되면 그 성능을 완벽하게 발휘하지 못하기 때문에 MR 유체 주입 시 댐퍼 내부로 공기가 유 입되지 않도록 최대한 주의하였다. MR 댐퍼 성능측정 장 비에 MR 댐퍼를 설치하여 Table 2의 실험조건에서 $\mathrm{MR}$ 댐퍼의 댐핑력을 측정하였다.

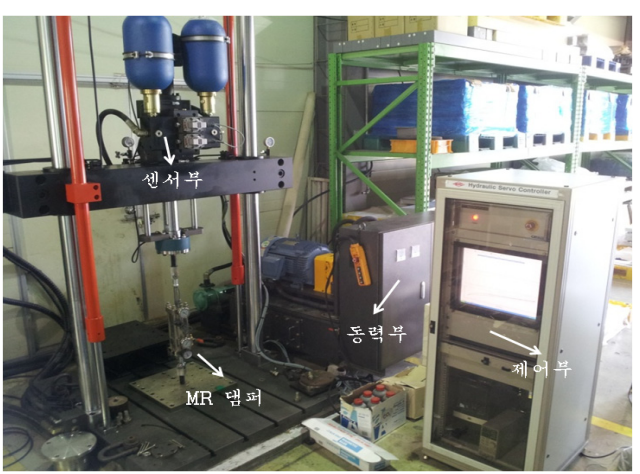

[Fig. 1] Experiment apparatus for MR damper performance

[Table 1] Specification of test system of MR damper

\begin{tabular}{|c|l|}
\hline Capacity & $\pm 150 \mathrm{kN}$ \\
\hline Tube bare & $\varnothing 125 \mathrm{~mm}$ \\
\hline Rod diameter & $\varnothing 80 \mathrm{~mm}$ \\
\hline Stroke & $\pm 25 \mathrm{~mm}$ \\
\hline Bed size & $1210(\mathrm{~W}) \times 1400(\mathrm{~L}) \times \mathrm{T} 90 \mathrm{~mm}$ \\
\hline Test space & $1000(\mathrm{~W}) \times 1400(\mathrm{~L}) \times 2000(\mathrm{H}) \mathrm{mm}$ \\
\hline Machine space & $1000(\mathrm{~W}) \times 1400(\mathrm{~L}) \times 4000(\mathrm{H}) \mathrm{mm}$ \\
\hline Hyd. pump unit & $30 \mathrm{~kW}(70 \mathrm{lpm}$, Water-Cooling $)$ \\
\hline
\end{tabular}
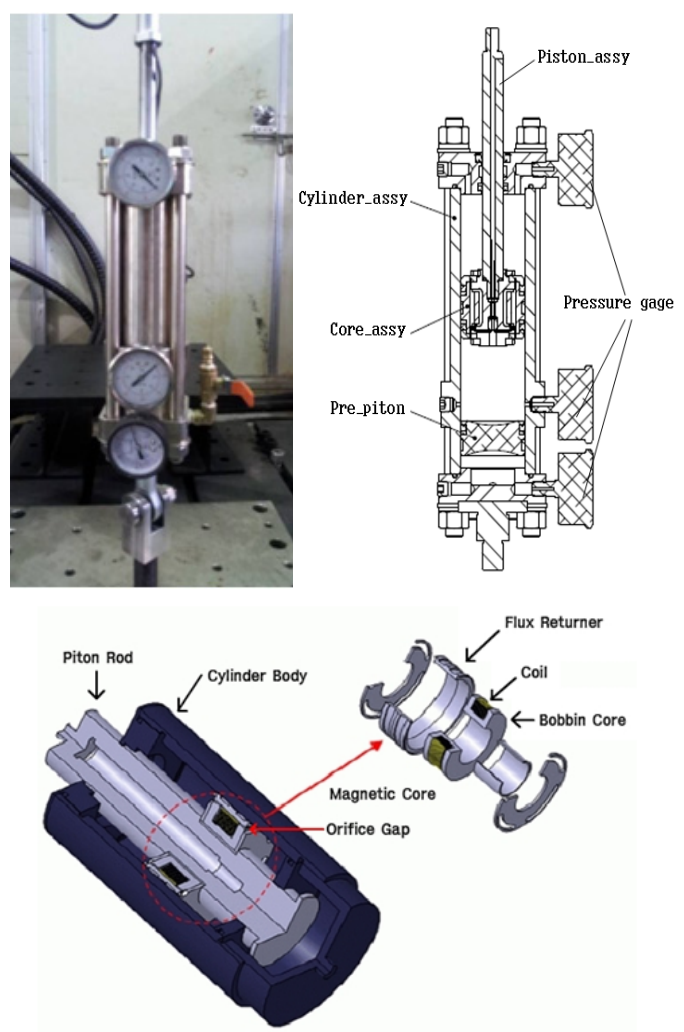

[Fig. 2] MR damper used in present experiment 
[Table 2] Experiment conditions of MR damper performance

\begin{tabular}{|c|l|}
\hline Density $\left(\mathrm{g} / \mathrm{cm}^{3}\right)$ & $1.3 / 1.5 / 1.7$ \\
\hline Viscosity $(\mathrm{cP})$ & $1000 / 10000$ \\
\hline Applied current $(\mathrm{A})$ & 0.3 \\
\hline Frequency $(\mathrm{Hz})$ & 1 \\
\hline Displacement $(\mathrm{mm})$ & \pm 5 \\
\hline \multirow{2}{*}{ MR damper $(\mathrm{mm})$} & Orifice length (O.L) : 6 \\
\cline { 2 - 2 } & Orifice gap (O.G) : 0.7 \\
\hline
\end{tabular}

\section{2 실험조건 및 실험방법}

실험은 $\mathrm{MR}$ 유체를 주입한 $\mathrm{MR}$ 댐퍼를 센서부에 설치 하고 일정한 전류를 인가한다. 유압에 의해 상하로 왕복 운동 하는 장치에 의해 MR 댐퍼에 힘이 가해지며 댐퍼 내의 항복응력은 로드셀을 통해 측정된다. MR 댐퍼 성능 비교 실험조건과 실험에 사용된 $\mathrm{MR}$ 유체의 밀도와 점도 는 Table 2에 나타나 있으며, 밀도는 $1.3 \mathrm{~g} / \mathrm{cm}^{3}, 1.5 \mathrm{~g} / \mathrm{cm}^{3}$, $1.7 \mathrm{~g} / \mathrm{cm}^{3} 3$ 종을, 점도는 $1000 \mathrm{cP}, 10000 \mathrm{cP} 2$ 종을 사용하 였다. 그리고 오리피스 길이와 오리피스 갭에 따른 댐핑 력을 비교하였다. 이를 위해 MR 댐퍼에 인가된 전류는 $0.3 \mathrm{~A}$, 댐퍼 내 코어부의 운동주파수는 $1 \mathrm{~Hz}$ 로 설정하였다.

$\mathrm{MR}$ 댐퍼 실험 시 센서부는 상용전류 $(60 \mathrm{~Hz})$ 의 간섭을 받으므로 실험데이터에 포함된 노이즈를 제거하기 위하 여 Matlab을 사용하였다. 노이즈 제거에는 lowpass filter 를 사용하여 $60 \mathrm{~Hz}$ 이상의 주파수 대역을 제거하여 정확 한 실험데이터를 획득하고자 하였다.

\section{3. 결과}

\section{1 밀도와 점도에 따른 댐핑력 변화}

Fig. 3 (a)과 (b)는 $\mathrm{MR}$ 유체의 점도가 $1000 \mathrm{cP}$ 와 $10000 \mathrm{cP}$ 에서 밀도가 $1.3 \mathrm{~g} / \mathrm{cm}^{3}, 1.5 \mathrm{~g} / \mathrm{cm}^{3}, 1.7 \mathrm{~g} / \mathrm{cm}^{3}$ 로 변화 할 때 Fig. 2의 MR 댐퍼에 대한 변위-힘을 보여준다. 이 때 오리피스 길이는 $6 \mathrm{~mm}$, 갭은 $0.7 \mathrm{~mm}$ 이다. Fig. 3 (a)에 서 점도가 $1000 \mathrm{cP}$ 인 $\mathrm{MR}$ 유체의 밀도가 $1.3 \mathrm{~g} / \mathrm{cm}^{3}$ 에서 $1.5 \mathrm{~g} / \mathrm{cm}^{3}$ 로 변하면 댐핑력은 약 $12 \%, 1.7 \mathrm{~g} / \mathrm{cm}^{3}$ 로 변하면 약 $37 \%$ 증가하였다. Fig. 3 (b)에서 점도가 $10000 \mathrm{cP}$ 인 $\mathrm{MR}$ 유체의 밀도가 $1.3 \mathrm{~g} / \mathrm{cm}^{3}$ 에서 $1.5 \mathrm{~g} / \mathrm{cm}^{3}$ 로 변하면 댐핑력은 약 $28 \%, 1.7 \mathrm{~g} / \mathrm{cm}^{3}$ 로 변하면 약 $46 \%$ 증가하였다. 이는 MR 유 체의 밀도와 점도가 증가하면 MR 댐퍼의 댐핑력이 강해 지는 것을 의미한다. $\mathrm{MR}$ 유체의 밀도 증가는 $\mathrm{MR}$ 유체 내의 자기장의 영향을 받는 $\mathrm{MR}$ 자성 파우더 입자들이 많아진 것을 의미하며, 그 영향으로 파우더들의 자기 결 속력이 커지게 된다. 또한 점도증가는 $\mathrm{MR}$ 유체의 전단응 력을 증가시키며, 그 결과 $\mathrm{MR}$ 댐퍼의 감쇠 댐핑력이 증 가된 것으로 이해할 수 있다.

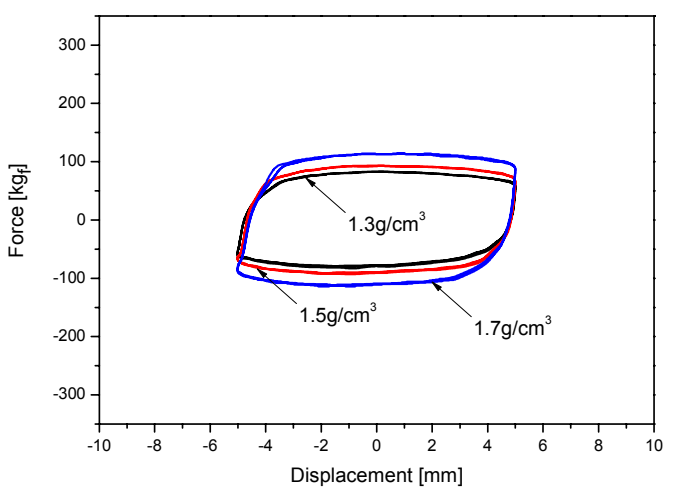

(a)

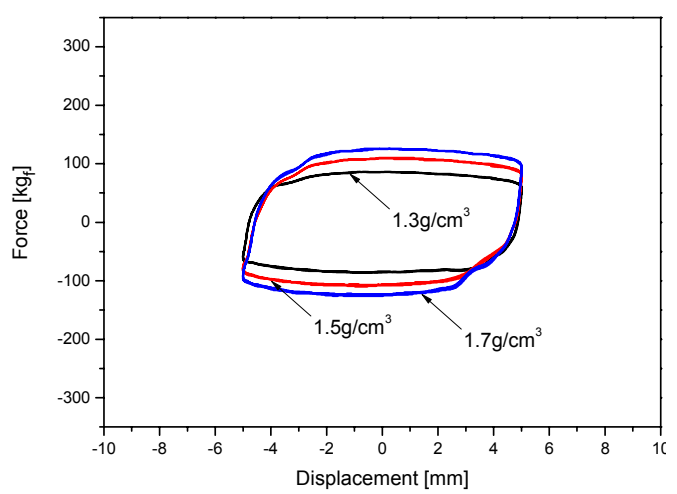

(b)

[Fig. 3] Force-displacement curve of MR damper by viscosity changer; (a) viscosity $1000 \mathrm{cP}$ (b) viscosity $10000 \mathrm{cP}$

Fig. 3 (a)와 (b)부터, 밀도 $1.3 \mathrm{~g} / \mathrm{cm}^{3}$ 인 $\mathrm{MR}$ 유체에서 점 도가 $1000 \mathrm{cP}$ 에서 $10000 \mathrm{cP}$ 로 변하면 $\mathrm{MR}$ 댐퍼의 댐핑력 은 약 $4 \%$ 증가하고, 밀도 $1.5 \mathrm{~g} / \mathrm{cm}^{3}$ 인 $\mathrm{MR}$ 유체에서 점도 가 $1000 \mathrm{cP}$ 에서 $10000 \mathrm{cP}$ 로 변하면 댐핑력은 약 $18 \%$ 증가 하였다. 그리고 밀도 $1.7 \mathrm{~g} / \mathrm{cm}^{3}$ 인 MR 유체에서 점도가 $1000 \mathrm{cP}$ 에서 $10000 \mathrm{cP}$ 로 변하면 댐핑력이 약 $11 \%$ 증가하 였다. 이들 결과로부터, 밀도가 낮은 경우보다 높은 경우 에 그리고 높은 점도에서 $\mathrm{MR}$ 댐퍼의 댐핑력은 더 크게 나타남을 알 수 있다.

\section{2 오리피스 길이와 갭에 따른 댐핑력 변화}

오리피스 길이(O.L)와 갭(O.G)의 변화에 따른 MR 댐 퍼의 댐핑력을 비교하기 전에 먼저 $\mathrm{MR}$ 댐퍼 오리피스 길이와 갭 변경에 대한 자속밀도를 검토하였다. 자속밀도 를 비교를 위해 오리피스 길이는 $6,12 \mathrm{~mm}$ 를 갭은 0.3 , $0.5,0.7 \mathrm{~mm}$ 의 6 종 댐퍼에 대한 오리피스 내 자기장을 Maxwell 전자장 프로그램을 이용하여 해석하였다. 해석 


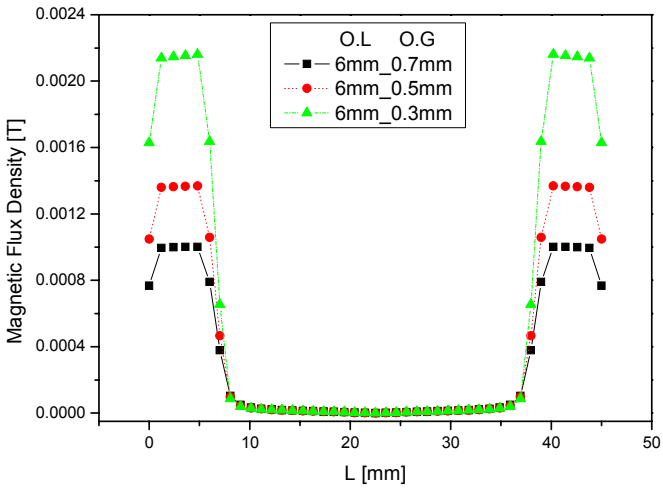

(a)

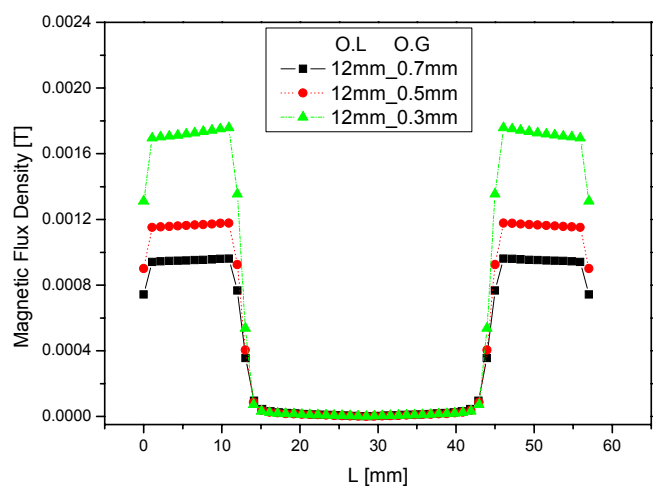

(b)

[Fig. 4] Magnetic flux density along orifice length and gap; (a) orifice length $6 \mathrm{~mm}$ (bobbin core length $45 \mathrm{~mm}$ ) (b) orifice length $12 \mathrm{~mm}$ (bobbin core length $57 \mathrm{~mm}$ )

시 MR 유체의 밀도는 $1.7 \mathrm{~g} / \mathrm{cm}^{3}$ 인 점도는 $1000 \mathrm{cP}$ 로 하였 다. 보빈 코어의 길이는 Fig. 2에 나타나있는 것처럼 오리 피스 길이가 $6 \mathrm{~mm}$ 일 때는 $45 \mathrm{~mm}$ 이며, 오리피스 길이가 $12 \mathrm{~mm}$ 일 때는 $57 \mathrm{~mm}$ 이다.

Fig. 4 (a)는 오리피스 길이가 $6 \mathrm{~mm}$ 이고 갭이 $0.3,0.5$, $0.7 \mathrm{~mm}$ 로 변할 때 오리피스에 인가되는 자속밀도를 보여 준다. 갭이 $0.7 \mathrm{~mm}$ 에서 $0.5 \mathrm{~mm}$ 로 줄어들면 자속밀도는 약 $37 \%$ 증가를 $0.7 \mathrm{~mm}$ 에서 $0.3 \mathrm{~mm}$ 로 줄어들면 약 $110 \%$ 증 가하였다. Fig. 4 (b)는 오리피스 길이가 $12 \mathrm{~mm}$ 이고 갭이 $0.3,0.5,0.7 \mathrm{~mm}$ 로 변할 때 오리피스에 인가되는 자속밀 도를 보여준다. 갭이 $0.7 \mathrm{~mm}$ 에서 $0.5 \mathrm{~mm}$ 로 줄어들면 자속 밀도는 약 $23 \%$ 증가를 $0.7 \mathrm{~mm}$ 에서 $0.3 \mathrm{~mm}$ 로 줄어들면 약 $83 \%$ 증가하였다. 즉, 오리피스 갭이 줄어들면 오리피스 내에 인가되는 자속밀도가 크게 증가하게 된다.

그리고 Fig. 4 (a)와 (b)로부터 오리피스 갭이 동일할 때 오리피스 길이에 따른 자속밀도를 비교할 수 있다. 갭

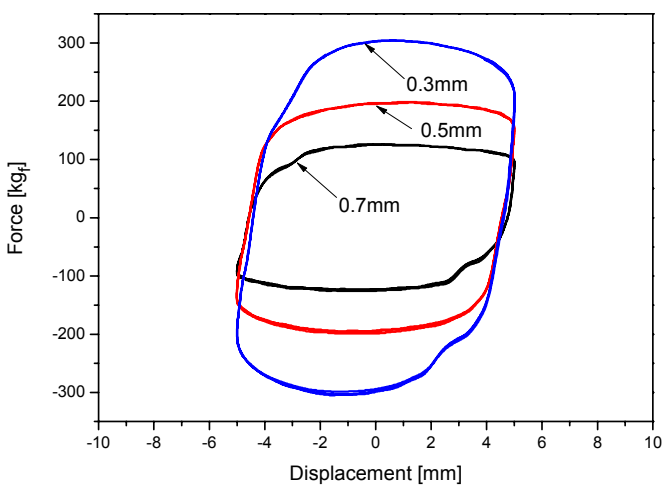

(a)

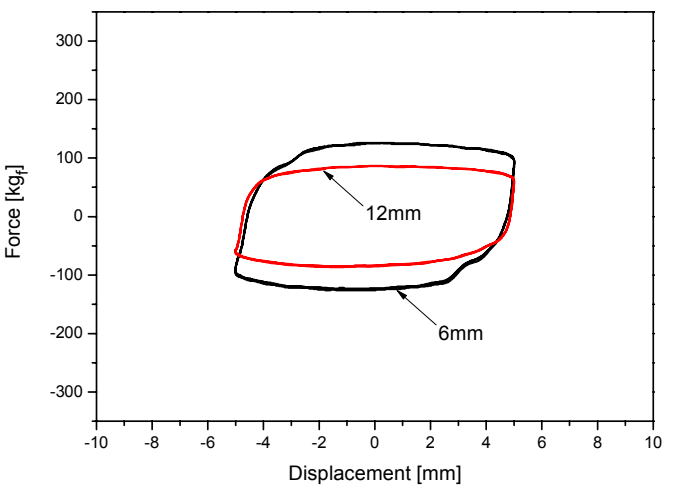

(b)

[Fig. 5] Force-displacement curve of MR damper by orifice length and gap; (a) orifice gap (b) orifice length

이 $0.7,0.5,0.3 \mathrm{~mm}$ 일 때, 길이가 $6 \mathrm{~mm}$ 에서 $12 \mathrm{~mm}$ 로 늘 어나면 자속밀도는 각각 약 $4,14,20 \%$ 정도 줄어들었다. 이는 오리피스 길이가 늘어나면 오리피스 내에 인가되는 자속밀도가 낮아진다는 것을 의미한다.

Fig. 5 (a)와 (b)는 밀도 $1.7 \mathrm{~g} / \mathrm{cm}^{3}$, 점도 $10000 \mathrm{cP}$ 에서 MR 댐퍼의 오리피스 갭과 길이 변화에 대한 변위-힘을 보여준다. Fig. 5 (a)에서 오리피스 갭이 $0.7 \mathrm{~mm}$ 에서 $0.5 \mathrm{~mm}$ 로 줄어들면 댐핑력은 약 $60 \%, 0.5 \mathrm{~mm}$ 에서 $0.3 \mathrm{~mm}$ 로 줄어들면 댐핑력은 약 $52 \%$ 증가하였다. 이는 $\mathrm{MR}$ 유 체의 밀도와 점도가 동일한 상태에서 자기장의 영향을 받는 오리피스의 갭 공간이 줄어들어 자기장에 의한 자 속밀도가 Fig. 4 (a)와 (b)에서 볼 수 있었던 것처럼 증가 하였기 때문이다. 이로부터 오리피스 갭이 감소하면 자기 장에 의한 댐핑력과 유체흐름으로 발생되는 점성 마찰력 이 너무 크게 증가하여 댐퍼 내 코어의 왕복운동이 원활 하지 않을 수 있으므로 MR 댐퍼 내 오리피스의 갭 사이 즈는 $\mathrm{MR}$ 댐퍼의 용량과 용도를 고려하여 $\mathrm{MR}$ 유체의 종 
류와 인가전류를 선정하여야 한다는 것을 알 수 있다.

Fig. 5 (b)에서 오리피스 길이가 $6 \mathrm{~mm}$ 에서 $12 \mathrm{~mm}$ 로 길 어지면 MR 댐퍼의 댐핑력은 약 $30 \%$ 정도 낮아진다. 이 는 $\mathrm{MR}$ 유체의 밀도와 점도가 동일한 상태에서 오리피스 의 길이가 늘어나면서 Fig. 4 (a)와 (b)에서 볼 수 있는 것 처럼 자기장에 의한 낮은 자속밀도 때문이다. MR 댐퍼의 오리피스 길이는 $\mathrm{MR}$ 유체의 종류와 인가되는 자기장 세 기에 따른 전자기 효과를 고려하여 선정되어야 할 것이 다. 실험결과로부터 MR 댐퍼 설계 시 MR 유체의 물성에 따른 특성과 오리피스 갭과 길이의 선정도 $\mathrm{MR}$ 댐퍼의 최적 설계를 위해서는 중요한 설계변수임을 알 수 있었다.

\section{4. 결론}

본 연구에서는 밀도 3 종, 점도 2 종의 $\mathrm{MR}$ 유체를 $\mathrm{MR}$ 댐퍼에 적용하여 $\mathrm{MR}$ 유체의 물성변화에 따른 $\mathrm{MR}$ 댐퍼 성능과 오리피스 치수 변경에 따른 $\mathrm{MR}$ 댐퍼의 성능을 비교하였다.

1) $\mathrm{MR}$ 유체의 점도 $1000 \mathrm{cP}$ 와 $10000 \mathrm{cP}$ 에서 밀도가 $1.3,1.5,1.7 \mathrm{~g} / \mathrm{cm}^{3}$ 로 변화할 때 $\mathrm{MR}$ 댐퍼의 댐핑력 은 점도 $1000 \mathrm{cP}$ 에서 밀도 $1.3 \mathrm{~g} / \mathrm{cm}^{3}$ 에서 $1.7 \mathrm{~g} / \mathrm{cm}^{3}$ 로 변 하면 약 $27 \%$ 그리고 점도 $10000 \mathrm{cP}$ 에서 밀도가 $1.3 \mathrm{~g} / \mathrm{cm}^{3}$ 에서 $1.7 \mathrm{~g} / \mathrm{cm}^{3}$ 로 변하면 약 $32 \%$ 댐핑력이 증 가하였다. $\mathrm{MR}$ 유체의 밀도와 점도증가는 $\mathrm{MR}$ 댐 퍼의 댐핑력을 변화시킬 수 있다는 것을 확인하였다.

2) 오리피스 갭과 길이가 줄어들면 오리피스 내에 인 가되는 자속밀도는 증가하였다. 오리피스 길이보다 는 갭에 대한 자속밀도 변화폭이 더 크게 나타났다.

3) 오리피스 갭이 $0.7 \mathrm{~mm}$ 에서 $0.3 \mathrm{~mm}$ 로 줄어들면 댐핑 력은 약 $143 \%$ 증가하였고 오리피스 길이가 $6 \mathrm{~mm}$ 에 서 $12 \mathrm{~mm}$ 로 길어지면 $\mathrm{MR}$ 댐퍼의 댐핑력은 약 $30 \%$ 정도 낮아졌다. 실험결과로부터 MR 댐퍼 설계 시 $\mathrm{MR}$ 유체의 물성과 오리피스 형상에 대한 체계적인 연구가 필요함을 확인하였다.

\section{References}

[1] Yoo, J. H. and Wereley, N. M., 2004. Performance of a magneto-rheololgical hydraulic power actuator system", J. Intell. Mater. Syst. Struct., Vol. 15, pp. 847-858

DOI: http://dx.doi.org/10.1177/1045389X04044536
[2] Gavin, H., Hoagg, J. and Dobossy, M., 2001. Optimal design of MR dampers, Proc. U.S.-Japan Workshop on Smart Structures for Improved Seismic Performance in Urban Regions, Seattle, WA, pp.225-236

[3] Goncalves, D., Koo, J. and Ahmadian, M., 2006, A review of the state of the art in Magneto-rheololgical fluid technologies (Part I : MR fluids and MR fluids models), The Shock and Vibration Digest, Vol. 38, No. 3, pp. 203-219 DOI: http://dx.doi.org/10.1177/0583102406065099

[4] Jeon, E. C., Park, J. W., Kim T. H. and Kim, S. Y., 2008, A study on the rheology characteristics of magnetic fluids in a circular pipe, Journal of the Korean Society of Manufacturing Process Engineers, Vol. 7, No. 2, pp. $38 \sim 44$

[5] Lee, S. H. Kim, K. Y., Baek, D. S., Kwon, Y. C., Park. S. J., 2013, Experimental study on Magnetic Flow Characteristics of MR Fluid, Journal of the Korea Academia-Industrial cooperation Society, Vol. 14, No. 8, pp. 3611-3616

DOI: http://dx.doi.org/10.5762/KAIS.2013.14.8.3611

[6] Baek, D. S., Lee, S. H. Kim, K. Y., Kwon, Y. C., 2013, Experimental Study on Physical Characteristics along Chemical Compositions of MR Fluid, Journal of the Korea Academia-Industrial cooperation Society, Vol. 14, No. 10, pp.4747-4752

\section{권 영 철(Young-Chul Kwon)}

[정회원]

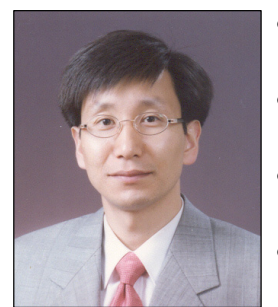

- 1989년 2월 : 부산대학교 정밀기 계공학과 (공학사)

- 1991년 8월 : 포스텍 기계공학과 (공학석사)

- 1996년 8월 : 포스텍 기계공학과 (공학박사)

- 1996년 9월 1999년 2월 : 한 국전력 전력연구원

- 1999년 3월 현재 : 선문대학교 기계공학과 교수

<관심분야>

냉동공조, 열전달 


\section{박 삼 진(Sam-Jin Park)}

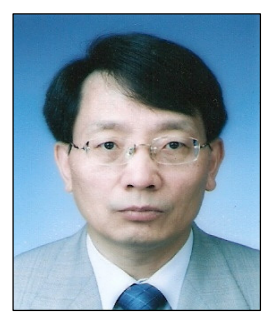

- 1977년 2월 : 서울대학교 기계설 계학과 (공학사)

- 1979년 8월 : 서울대학교 기계설 계학과 (공학석사)

- 1984년 1월 : Case Western Reserve Univ. (공학박사)

- 1984년 4월 1994년 2월 : 한 국기계연구원 책임연구원

- 1994년 3월 현재 : 선문대학교 기계공학과 교수

<관심분야>

기계설계, $\mathrm{CAD}$

\section{김 기 영(Ki-Young Kim)}

[준회원]

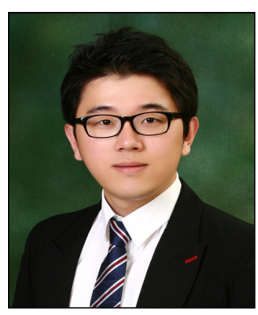

- 2012년 2월 : 선문대학교 기계공 학과 (공학사)

- 2012년 3월 현재 : 선문대학교 기계공학과 (대학원)

<관심분야>

냉동공조, 열교환기, 전산해석

백 대 성(Dae-Sung Baek)

[정회원]

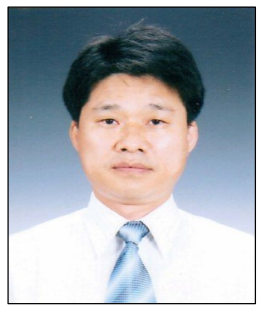

- 1990년 2월 : 숭실대학교 화학과 (이학사)

- 2008년 8월 현재 : (주) RMS 테크놀러지(주) 개발팀장

- 2013년 3월 현재 : 선문대학교 기계공학과 (대학원)
이 석 현(Seok-Hyun Lee)

[준회원]

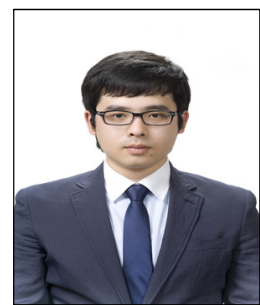

- 2013년 2월 : 선문대학교 기계공 학과 (공학사)

- 2013년 3월 현재 : 선문대학교 기계공학과 (대학원)

<관심분야>

냉동공조, 전산해석

<관심분야>

자성유체 및 응용 